\title{
Factors Attrilbuted to Fatal Occupational Accidents in a Period of 5 Years Preceding the Athens 2004 Olympic Games
}

\author{
Panagiota Katsakiori \\ Emmanuel Manatakis \\ Stavros Goutsos \\ George Athanassiou
}

Department of Mechanical Engineering and Aeronautics, University of Patras, Greece

This study aimed to determine the factors attributed to occupational fatalities occurring in the region of East Attica, Greece, in all industry types over a 5-year period preceding the 2004 Olympic Games. Questionnaires, based on the attribution theory, were completed by labor inspectors and were analyzed with principal component analysis. The results showed that most accidents occurred in the construction industry due to large-scale civil works, which took place in East Attica prior to the 2004 Olympic Games. Poor work practices arising from lack of orientation and job training, performance pressure and workers' inexperience associated with knowledge- and skill-based errors were revealed by the questionnaire as the most common factors attributed to occupational fatalities. Our findings help to identify areas where prevention efforts should be directed to effectively manage safety in Greece.

occupational accidents attribution theory human error

\section{INTRODUCTION}

In the safety profession, many methodologies, which aspire to describe the process and the causation of occupational accidents, frequently rely on the chain of events model $[1,2]$. The causation model developed by Heinrich depicts the route to the accident as being analogous to a set of dominoes standing in a row next to one another [1]. This model, also known as the domino theory, implies a linear one-by-one progression of events leading to the accident and it is a variant of the process model where an accident is seen as a sequence of events [3]. The disadvantages of the domino theory are that any interruption will stop the sequence of events and that there can be just one cause for a given accident. Besides, in this model, emphasis is given to the prevalence of human error, which is the key factor for the falling of the dominoes. According to Heinrich, $88 \%$ of all accidents are caused by people's unsafe acts.

Bird considerably improved Heinrich's model re-examining the nature of the events and minimizing the significance of human error [2]. He continued the use of dominoes, but recognized the multiplicity of causes leading up to an accident and introduced the multiple causation model. For a single accident, there may be many contributory factors, and there are certain combinations of the contributory factors that may cause an accident. According to his theory, the contributory factors can be grouped into behavioral and environmental. The behavioral factors pertain to the employee within the organization of human resources

\footnotetext{
The writers thank the participant labor inspectors of East Attica, Greece, who completed the questionnaires and provided the necessary data to perform this study.

Correspondence and requests for offprints should be sent to Panagiota Katsakiori, 31-33 Xiou St., GR 153 43, Athens, Greece. E-mail: <pkatsak@upatras.gr>.
} 
such as lack of skills and lack of knowledge, whereas the environmental factors include the work environment, work procedures and the management practices in operation. Grouping the contributory factors into behavioral and environmental suggests a shift in our thinking about safety and occupational accidents. These factors must not be overlooked when identifying the causation of workplace accidents. Thinking about behavioral and environmental factors is a simple way to view human factors. In other words, human factors refer to environmental, organizational and job factors, as well as human and individual characteristics, which influence behavior at work in a way which can affect health and safety [4].

Within the chain of events leading to an accident, the weak link is the point that leads the investigators to identify what went wrong and why the accident was allowed to occur. The weak link may identify a specific human error that was made and the person who made it [5]. People and/or their actions are thought of as weak links in the performance chain.

The way accidents are analyzed and safety directions are given derive more from attribution processes than from actual causes. Attribution theory is the area of social psychology concerned with how people process information in determining the causality of events to facilitate understanding and to shape future behaviour [6]. The literature on attribution suggests that unexpected negative events generate a higher number of attributions [7, 8, 9]. This explains the fact that attribution theory has been examined in the context of workplace safety [10]. Accidents at work are negative events and instigate information search and attribution formulation [11].

There are two views on human contribution to accidents in the human factors approach. The old view sees human error as the cause of most accidents, whereas the new view sees human error connected to features of people, tools, tasks and operating environment [12]. The new view of human error encourages the investigation of factors that easily disappear behind the human error such as long-standing organizational deficiencies, design problems and procedural shortcomings. According to Rasmussen, errors are divided into skill-based errors, which occur through a disruption in the program of actions, usually due to changes in attention level; rulebased errors, which regard failure to apply appropriately expertise; and knowledge-based errors, which occur due to lack of expertise [13].

We hypothesized that while the attribution theory had been well developed, there were not enough studies on the working field and we addressed this hypothesis by studying the fatal occupational accidents in the region of East Attica, Greece. In view of the attribution theory and on the new view of human error, the purpose of this study was to determine the specific factors attributed to fatal occupational accidents that occurred in East Attica between 1999 and 2003. Consequently, by grouping the factors into external (environmental, organizational and job) and internal (human and individual characteristics), we researched the interface between them and we compared the influence of both categories.

\section{METHODOLOGY OF THE STUDY}

In Greece, health and safety legislation (L. $1568 / 85^{1}$, P.D. $17 / 96^{2}$ ) requires the employer to report any occupational fatality to the appropriate Centre of Prevention of Occupational Risk within $24 \mathrm{hrs}$. Upon receipt of the employer's report, one or two labor inspectors investigate the accident in the workplace and, on the basis of the conditions of the accident and on witnesses' testimonies, they write a formal accident investigation report, which they transmit to the appropriate police

\footnotetext{
${ }^{1}$ Health and safety of employees. In: Legislative framework for health and safety of employees. Athens, Greece: Ministry of Labor and Social Security; 1996. p. 7-25. In Greek.

${ }^{2}$ Measures for the improvement of health and safety of employees at work in compliance with the European guidelines 89/391/EC and 91/383/EC. In: Legislative framework for health and safety of employees. Athens, Greece: Ministry of Labor and Social Security; 1996. p. 39-52. In Greek.
} 
department. This report serves as a basis for subsequent legal action [14].

Labor inspectors, in charge of the accident investigation, keep a file in the Center of Prevention of Occupational Risk, containing all data collected regarding the accident so that they can have access to it anytime it is necessary. The labor inspectors, who had undertaken the investigation and had written the investigation reports, were asked to complete a questionnaire. They did that in October 2004, shortly after the end of the Olympic Games. The questionnaire was adapted and modified for the purposes of the present study regarding certain questions (Appendix on p. 292) [15]. Those questions referred to the perception of the impact of uncontrollable supernatural forces on the occurrence of the accident and the perception of the impact of situations where workplace conditions have led workers to accept the inevitability of the accidents. Those items could not be measured by labor inspectors and therefore were excluded from the analysis.

Before the completion of the questionnaire, the labor inspector in charge of the specific fatal occupational accident was asked to examine thoroughly the file containing all data regarding the specific accident. Then, he or she was asked to undergo the attribution process, through the questionnaire and make inferences about the causality of the accident. For the needs of our research, contributing factors were divided into external and internal causal variables. External causal variables reflected the environmental, organizational and job factors. Internal causal variables reflected the human and individual characteristics of the accident victims. The participants responded to a questionnaire of 25 questions using a 5-point response format (1-very little, 2-quite little, 3-neutral, 4-quite much, 5-very much), which allowed them to rate the influence of contributing factors, classified as external and internal causal variables.

The statistical factor analysis was performed with SPSS version 11.0. The method of principal component analysis (PCA) was applied [16, 17, 18]. Five questions referring to the external causal factor-low wages-and to the internal causal factors-prone to accidents, urge to impress co-workers, tiredness/fatigue and willful violations-were excluded because labor inspectors did not mark them for most accidents in during the completion of the questionnaire. PCA with rotation to a Varimax criterion was applied for the 20 (11 external and 9 internal) remaining causal factors.

\section{RESULTS}

The number of fatal occupational injuries, from 1999 until 2003, is shown in Table 1. The year with the highest fatality was 2002, whereas the fewest deaths occurred in 2001.

TABLE 1. Fatal Occupational Injuries (FOI) by year in East Attica, Greece

\begin{tabular}{lc}
\hline Year & No. of FOI \\
\hline 1999 & 12 \\
2000 & 10 \\
2001 & 9 \\
2002 & 19 \\
2003 & 13 \\
Total & 63 \\
\hline
\end{tabular}

The leading causes of fatalities were falls from a height $(58.73 \%)$, followed by exposure or contact with electric current (12.69\%) and being caught in between and clamped into or between objects $(11.11 \%)$.

TABLE 2. Fatal Occupational Injuries (FOI) by Type in East Attica, Greece, in 1999-2003

\begin{tabular}{lc}
\hline Injury Type & No. of FOI \\
\hline $\begin{array}{l}\text { Exposure or contact with electric } \\
\quad \text { current }\end{array}$ & 8 \\
Falls from a height & 37 \\
$\begin{array}{l}\text { Strikes from falling objects (collapses, } \\
\quad \text { slips, etc.) }\end{array}$ & 6 \\
$\begin{array}{l}\text { Being caught in between and clamped } \\
\quad \text { into or between objects }\end{array}$ & 7 \\
$\begin{array}{l}\text { Exposure or contact with hazardous } \\
\quad \text { substances (inhalation, ingestion or }\end{array}$ & 2 \\
$\quad$ absorption of harmful substances) & \\
Other injury types & 3 \\
Total & 63 \\
\hline
\end{tabular}

Sixty-three questionnaires were completed and 50 of them referred to fatal occupational accidents 
TABLE 3. Rotated Component Matrix

\begin{tabular}{llcc}
\hline & & \multicolumn{2}{c}{ Components } \\
\cline { 3 - 4 } Causal Variables & & $\mathbf{1}$ & $\mathbf{2}$ \\
\hline excauf6 & pressure from management/supervisor & 0.147 & 0.778 \\
excauf9 & victim new to the situation in the workplace & $-2766 \mathrm{E}-02$ & 0.810 \\
excauf11 & lack of right protective equipment & 0.849 & $8096 \mathrm{E}-02$ \\
excauf12 & ambiguity and task difficulty & 0.758 & $-1632 \mathrm{E}-02$ \\
intcauf5 & failure to use protective equipment & 0.843 & 0.125 \\
\hline
\end{tabular}

Notes. Shaded cells represent factor loadings with the highest values.

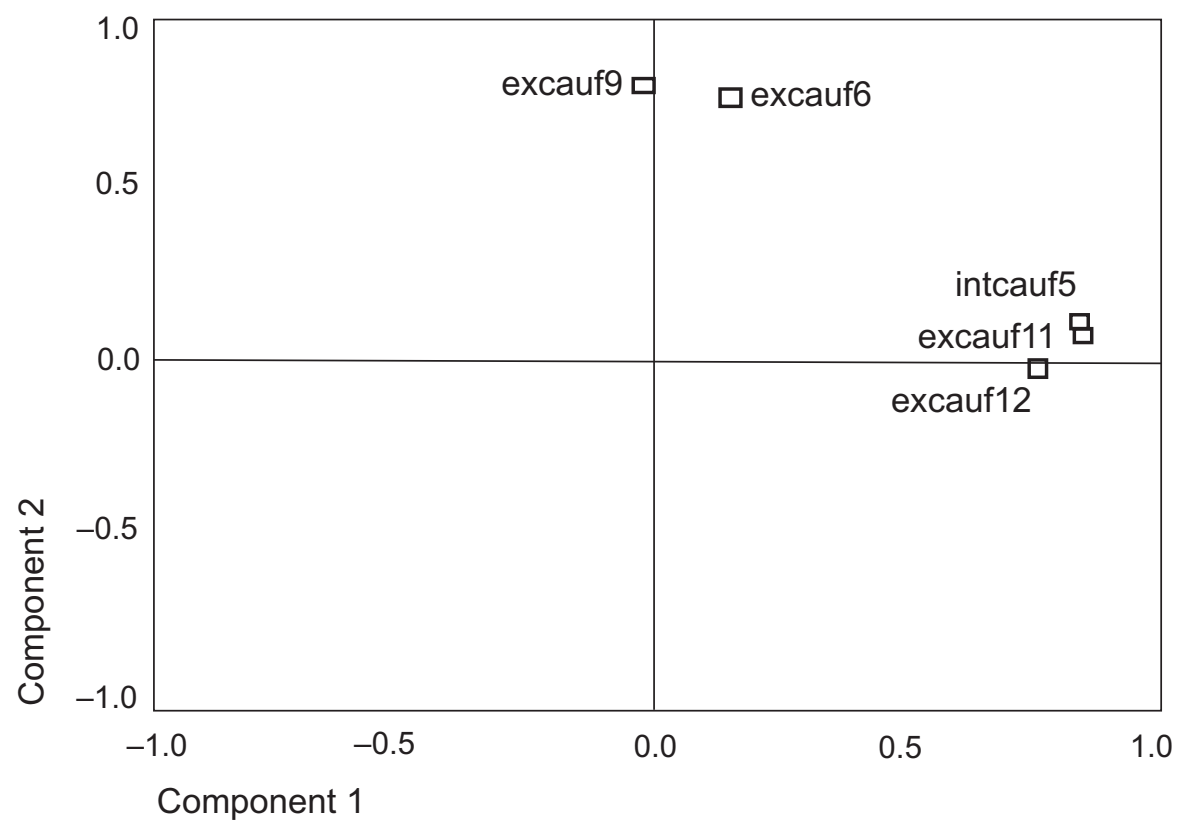

FIGURE 1. Components of the rotated factors.

in the construction sites. Factor analysis was used to help identify the underlying cluster of factors attributed to the fatal occupational accidents. Test of factorability was performed with KaiserMeyer-Olkin's measure of sampling adequacy. Rotated factor matrix contains the factor loadings after the application of PCA with rotation to a Varimax criterion.

The components of the rotated factors are presented in Figure 1. The factors are an aggregation of individual variables. Factor 1 expresses variables excauf11 (0.849), excauf12 (0.758), intcauf5 (0.843), i.e., lack of right protective equipment, ambiguity and task difficulty, and failure to use protective equipment, respectively. Factor 2 interprets variables excauf6 (0.778), excauf9 (0.810), i.e., pressure from management/ supervisor and victim new to the situation in the workplace, respectively.

\section{DISCUSSION}

In this study, we determined factors attributed to the fatal occupational accidents in East Attica, Greece, in view of the attribution theory and the new view on human error. For this purpose, we investigated the factors that are hidden behind the human error such as organizational shortcomings and we confirmed the multicausal nature of accidents. To our knowledge, this study represents one of the first attempts to investigate factors attributed to occupational accident causation in Greece with specificities such as 
large-scale public works, time pressure, unskilled personnel, etc.

The process of analyzing accidents revolves around making internal (e.g., unsafe behaviour) or external (e.g., unsafe conditions) attributions of causality. The results from the analysis suggested that each occupational accident was the result of a network of causal factors, and especially external (i.e., environmental, organizational and job) factors. Labor inspectors perceived external factors to be primarily responsible for accident occurrence. This is not in line with the view of Jones and Nisbett, who exposed the attribution differences between actors and observers to an event, with actors more focused on external causes (associated with the context of the situation) and observers more focused on internal causes (connected to the individuals) [19]. In our case, labor inspectors focused on external causes, despite the fact that they were observers to the accident event.

External causes such as provision of equipment (unavailability of appropriate protective equipment) as well as work design and organization (unclear expectations and ambiguity, tight work and production schedules for workers, misassignment of the victim) were shown to contribute to accident occurrence. On the other hand, only one internal causal factor (failure to use protective equipment) was found. This study confirms the contribution of external factors within the workplace, job and management to accidental occurrence.

Factor 1 is associated with the orientation and worker job training by the organization. Safety issues are among the topics that must be covered in an organization's orientation program [20]. Additionally, training must follow the orientation program, because training employees is a learning process leading to the enhancement of the workers' performance. Poor work practices were the most common precursors of human error precipitating fatalities, as demonstrated by Feyer and Williamson [21] and Feyer, Williamson and Cairns [22]. In our study, the application of poor work practices most probably arises from lack of orientation and job training from the organization.
Most accidents analyzed in this study took place in the construction industry. The working environment in this type of industry is constantly changing, the construction sites exist for a relatively short time and the activities and inherent risks change daily. In addition, there is usually a high turnover in the workforce due to the hard nature of the work, and this may be associated with lack of safety awareness. All those characteristics make workers vulnerable to occupational risks and there is a serious need for orientation and training for these categories of workers.

The nature of the construction industry is also widely fragmented because of the many subcontractors, many small firms and selfemployed labor. This fragmentation militates against the establishment of widely accepted safe working practices. Lack of right protective equipment (0.849) arose from a deliberate management decision which provided an unsafe environment for doing work and which did not conform to the legislative requirements. Failure to use protective equipment (0.843) was an individual worker practice, which was expected as the right protective equipment was lacking. Management practice and individual worker practice interacted with the nature of work, which included ambiguous and difficult tasks (0.758). The worker may have lacked the knowledge to execute them the safest way. Our study accurately predicted the relationship between management and individual worker practices as well as their association with human error. Management practices have been associated with knowledgebased errors, whereas skill-based errors have been most strongly associated with individual worker practices involving the use of protective equipment [22]. Furthermore, we observed that lack of right protective equipment and failure to use protective equipment were associated with the most frequent injury type, which is falling from a height (58.73\% of all accidents).

Factor 2 expresses management practices related to the specificities of the product. In the construction industry, the product is the specific construction project. The preoccupation to perform the project as soon as possible became 
more obvious the years preceding the Olympic Games due to time pressure. We observed that the psychological factor (i.e., pressure exerted over the worker to execute the work as fast as possible), which was found to be quite high (0.778), in combination with the inexperience of the worker in the specific type of work, which was found to be 0.810 , contributed decisively to the occurrence of accidents. This finding is in agreement with Wright's [23] and Wagenaar and Groeneweg's [24] observations. Wright [23] reviewed the causes of fatal accidents involving offshore oil workers in the British sector of the North Sea and reported a strong pressure within the organization to complete the work as quickly as possible. Along similar lines, Wagenaar and Groeneweg [24] found that human information processing errors occurred more frequently in the presence of high situational stress than would be expected by chance. Performance pressure over the worker was a management practice. Accident victim new to the work situation is more liable to knowledge-based errors, which occur through lack of expertise; this is in line with Feyer et al.'s views that management practices are associated with knowledge-based errors [22].

East Attica, Greece, had a lot of construction activities due to large-scale public works which took place for the 2004 Olympic Games. In 2000 and 2001, the number of fatal accidents declined (10 and 9, respectively) and in 2002, the number of injuries increased (19) mainly due to the acceleration of the construction activities taken place for the 2004 Olympic Games. In 2002, fatal injuries occurred predominantly in the construction sites of the Olympic projects. In 2003, there was a decline in the number of injuries (13) due to the effort put in by labor inspectors to ensure safety in the construction of the Olympic projects, which bore fruit although the time pressure remained. The initiatives taken by labor inspectors to ensure the need for a safe working environment resulted in the prevention of a number of accidents in the construction sites.

Going back to Table 3, which is the result of PCA with rotation to a Varimax criterion, we note that factor 2 interprets two variables, excauf6 $(0.778$, pressure from management/supervisor) and excauf9 (0.810, victim new to the situation in the workplace). The observed decline in the number of fatal injuries, due to the increased labor inspectors' presence and inspection on work sites, differentiates the impact of the aforementioned variables in factor 2 . This means that variable excauf9 had an increased contribution in explaining factor 2 against variable excauf6. In other words, although pressure to finish the public works increased as the date of the inauguration for the Olympic Games was nearest than ever, the number of fatal injuries decreased. Fatal injuries were not zero because variable excauf6 (victim new to the situation of in the workplace) is important in any workplace.

Poor work practices (management and individual worker) were the most common attributing factors leading to occupational fatalities associated with knowledge- and skillbased errors. Each occupational accident was the result of a complex network of factors that related to one another and that were not equivalent in causal importance. The combination of those factors contributed to accident occurrence.

\section{CONCLUSIONS}

From this preliminary study, which identifies areas where prevention efforts should be directed to effectively manage safety in Greece and which might guide further research, the following can be concluded:

- the importance of orientation and job training among employees is confirmed;

- provision of the right protective equipment and supervision of employees using it would seem to be a sufficiently adequate measure; in fact, this produces a distinct improvement in the working conditions;

- it seems essential to reduce performance pressure over the worker;

- the worker's inexperience is important in any workplace.

Additionally, the analysis of fatal accidents with the use of questionnaires, completed by labor inspectors in charge of every accident investigated, allowed us to probe interesting 
topics raised by respondents and seems to be a good starting point to reconstruct the role that people have in accidents.

\section{REFERENCES}

1. Heinrich WH. Industrial accident prevention. New York, NY, USA: McGraw-Hill; 1941.

2. Bird FE, Loftus RG. Loss control management. Loganville, GA, USA: International Loss Control Institute; 1976.

3. Kjellen U, Larsson TJ. Investigating accidents and reducing risks-a dynamic approach. J Occup Accid. 1981;3(2): 129-40.

4. Health and Safety Executive (HSE). Reducing error and influencing behavior. Suffolk, UK: HSE Books; 1999.

5. Goldberg AT, editor. Rethinking the chain of events analogy for incidents. Proceedings of ASSE Professional Development Conference. Denver, CO, USA: American Society of Safety Engineers (ASSE); 2003.

6. Lacroix DV, DeJoy DM. Causal Attributions to effort and supervisory response to workplace accidents. J Occup Accid. 1989;11(2):97-109.

7. Nisbett R, Ross L. Human inference: strategies and shortcomings of social judgment. Englewood Cliffs, NJ, USA: Prentice-Hall; 1985.

8. Jones EE. Interpersonal perception. New York, NY, USA: Freeman; 1990.

9. Melia JL, Chisvert M, Pardo E. Procedural model of the attributions and attitudes towards work accidents: measurement and intervention strategies. J Work Organ Psy. 2001;17(1):63-90.

10. DeJoy DM. Attributional processes and hazard control management in industry. J Safety Res. 1985;16(2):61-71.

11. DeJoy DM. Managing safety in the workplace: an attribution theory analysis and model. J Safety Res. 1994;25(1):3-17.
12. Dekker SWA. Reconstructing human contributions to accidents: the new view on error and performance. J Safety Res. 2002; 33(3):371-85.

13. Rasmussen J. Human errors: a taxonomy for describing human malfunction in industrial installations. J Occup Accid. 1982;4(2-4):311-33.

14. Von Richthofen W. Labour inspection-a guide to the profession. Geneva, Switzerland: International Labour Office; 2002.

15. Gyekye SA. Causal attributions of Ghanaian industrial workers for accident occurrence: miners and non-miners perspective. J Safety Res. 2003;34(5):533-8.

16. Moser CA, Kalton G. Survey methods in social investigation. New York, NY, USA: Basic Books; 1972.

17. Jolliffe IT. Principal component analysis. New York, NY, USA: Springer; 1986.

18. Tabachnick BG, Fidell LS. Using multivariate statistics. New York, NY, USA: Harper Collins College; 1996.

19. Jones EE, Nisbett RE. The actor and the observer, divergent perceptions of the causes of behavior. New York, NY, USA: General Learning Press; 1971.

20. Byars LL, Rue LW. Human resource management. 6th ed. New York, NY, USA: McGraw-Hill; 2000.

21. Feyer A-M, Williamson AM. A classification system for causes of occupational accidents for use in preventive strategies. Scand J Work Environ Health. 1991;17(5): 302-11.

22. Feyer A-M, Williamson AM, Cairns DR. The involvement of human behavior in occupational accidents: errors in context. Saf Sci. 1997;25(1-3):55-65.

23. Wright C. Fatal accidents in the oil industry. Sociol Rev. 1986;4:265-89.

24. Wagenaar WA, Groeneweg J. Accidents at sea: multiple causes and impossible consequences. Int J Man-Mach Stud. 1987; 27:587-98. 


\section{Appendix}

\section{Questionnaire [15]}

How would you rate the influence of the following variables as contributory factors to the accident?

Response alternatives: 1—very little, 2—quite little, 3-not much and not little (neutral), 4-quite much, 5-very much.

When a factor does not contribute at all, do not mark anything.

\section{External causal variables (environmental, organizational and job factors)}

$\begin{array}{ll}\text { excauf1 } & \text { low wages } \\ \text { excauf2 } & \text { time and trouble saving } \\ \text { excauf3 } & \text { work overload } \\ \text { excauf4 } & \text { unsafe or defective equipment and facilities } \\ \text { excauf5 } & \text { inadequate training, orientation and supervision } \\ \text { excauf6 } & \text { pressure from management/supervisor } \\ \text { excauf7 } & \text { poor co-ordination } \\ \text { excauf8 } & \text { work and production schedule } \\ \text { excauf9 } & \text { victim new to the situation in the workplace } \\ \text { excauf10 } & \text { poor housekeeping } \\ \text { excauf11 } & \text { lack of right protective equipment } \\ \text { excauf12 } & \text { ambiguity and task difficulty }\end{array}$

$\begin{array}{lllll}1 & 2 & 3 & 4 & 5 \\ 1 & 2 & 3 & 4 & 5 \\ 1 & 2 & 3 & 4 & 5 \\ 1 & 2 & 3 & 4 & 5 \\ 1 & 2 & 3 & 4 & 5 \\ 1 & 2 & 3 & 4 & 5 \\ 1 & 2 & 3 & 4 & 5 \\ 1 & 2 & 3 & 4 & 5 \\ 1 & 2 & 3 & 4 & 5 \\ 1 & 2 & 3 & 4 & 5 \\ 1 & 2 & 3 & 4 & 5 \\ 1 & 2 & 3 & 4 & 5\end{array}$

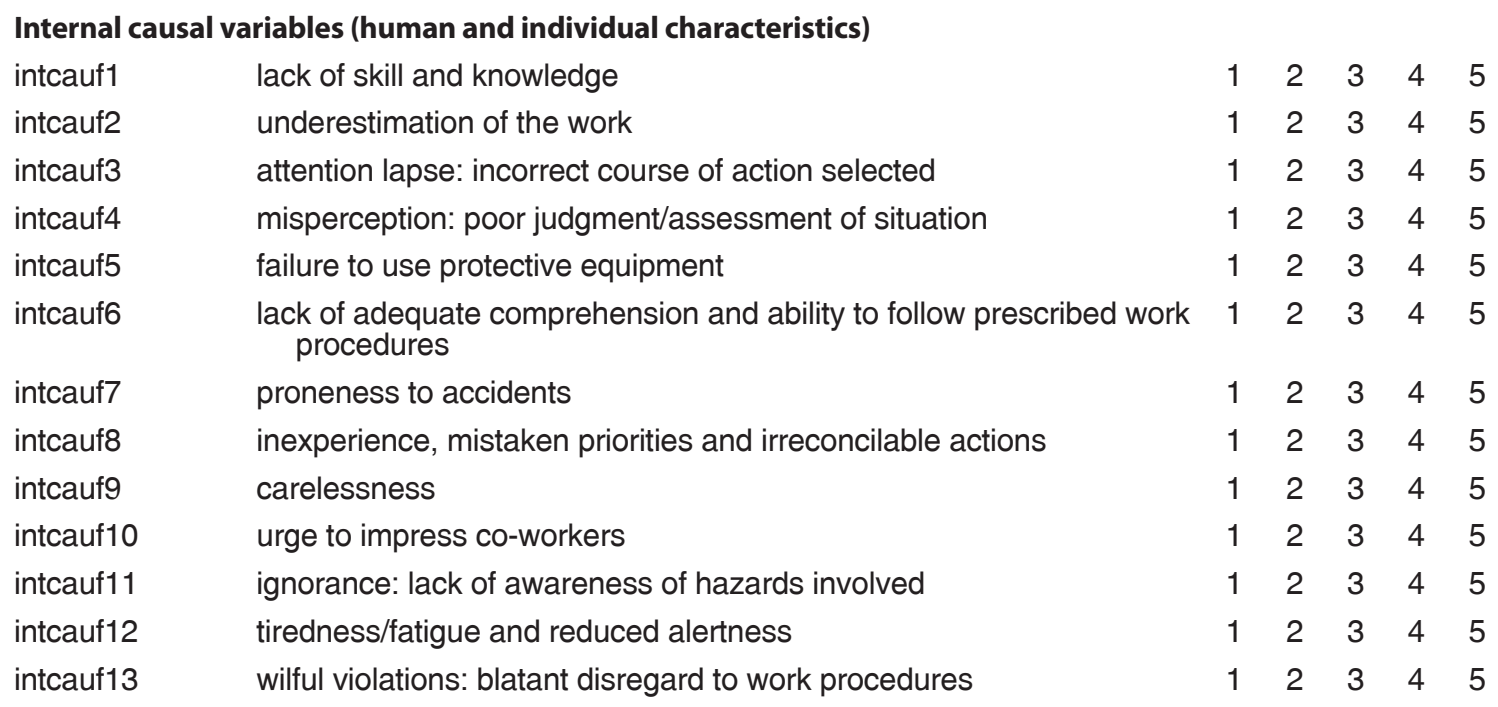

